\title{
Coexpression of GM-CSF and antigen in DNA prime-adenoviral vector boost immunization enhances polyfunctional $C D 8+T$ cell responses, whereas expression of GM-CSF antigen fusion protein induces autoimmunity
}

\author{
Matthias Tenbusch ${ }^{1}$, Seraphin Kuate ${ }^{1,3}$, Bettina Tippler ${ }^{1}$, Nicole Gerlach ${ }^{2}$, \\ Simone Schimmer ${ }^{2}$, Ulf Dittmer ${ }^{2}$ and Klaus Überla*1
}

Address: ${ }^{1}$ Department of Molecular and Medical Virology, Ruhr-University Bochum, 44801 Bochum, Germany, ${ }^{2}$ Institute of Virology, University of Duisburg-Essen, 45122 Essen, Germany and ' ${ }^{2}$ mmune Biology of Retroviral infections, VB, CCR, NCI, NIH, Bethesda, USA

Email: Matthias Tenbusch - matthias.tenbusch@rub.de; Seraphin Kuate - kuates@mail.nih.gov; Bettina Tippler - bettina.g.tippler@ruhr-unibochum.de; Nicole Gerlach - nicole.gerlach@uni-duisburg-essen.de; Simone Schimmer - simone.schimmer@uni-duisburg-essen.de; Ulf Dittmer - ulf.dittmer@uni-due.de; Klaus Überla* - klaus.ueberla@ruhr-uni-bochum.de

* Corresponding author

\section{Published: II April 2008}

BMC Immunology 2008, 9:13 doi:10.1 186/147|-2172-9-13
Received: 7 August 2007

Accepted: II April 2008

This article is available from: http://www.biomedcentral.com/I47I-2/72/9//3

(c) 2008 Tenbusch et al; licensee BioMed Central Ltd.

This is an Open Access article distributed under the terms of the Creative Commons Attribution License (http://creativecommons.org/licenses/by/2.0), which permits unrestricted use, distribution, and reproduction in any medium, provided the original work is properly cited.

\begin{abstract}
Background: Granulocyte-macrophage colony-stimulating factor (GM-CSF) has shown promising results as a cytokine adjuvant for antiviral vaccines and in various models of tumor gene therapy. To explore whether the targeting of antigens to GM-CSF receptors on antigen-presenting cells enhances antigen-specific CD8 T-cell responses, fusion proteins of GM-CSF and ovalbumin (OVA) were expressed by DNA and adenoviral vector vaccines. In addition, bicistronic vectors allowing independent expression of the antigen and the cytokine were tested in parallel.

Results: In vitro, the GM-CSF ovalbumin fusion protein (GM-OVA) led to the better stimulation of OVA-specific CD8+ $T$ cells by antigen-presenting cells than OVA and GM-CSF given as two separate proteins. However, prime-boost immunizations of mice with DNA and adenoviral vector vaccines encoding GM-OVA suppressed CD8+ T-cell responses to OVA. OVA-specific IgG2a antibody levels were also reduced, while the $\lg \mathrm{GI}$ antibody response was enhanced. Suppression of CD8+ T cell responses by GM-OVA vaccines was associated with the induction of neutralizing antibodies to GM-CSF. In contrast, the coexpression of GM-CSF and antigens in DNA prime adenoviral boost immunizations led to a striking expansion of polyfunctional OVA-specific CD8+ $T$ cells without the induction of autoantibodies.

Conclusion: The induction of autoantibodies suggests a general note of caution regarding the use of highly immunogenic viral vector vaccines encoding fusion proteins between antigens and host proteins. In contrast, the expansion of polyfunctional OVA-specific CD8+ T cells after immunizations with bicistronic vectors further support a potential application of GM-CSF as an adjuvant for heterologous prime-boost regimens with genetic vaccines. Since DNA prime adenoviral vector boost regimenes are presently considered as one of the most efficient ways to induce CD8+ T cell responses in mice, non-human primates and humans, further enhancement of this response by GM-CSF is a striking observation.
\end{abstract}




\section{Background}

The induction of strong CTL responses by prophylactic and therapeutic vaccines is considered necessary for the control of chronic viral infections and cancer [1-3]. Genetic vaccines seem to be promising tools, since the expression of antigen by the vaccinee leads to improved MHC-I restricted cellular immune responses. DNA vaccines have been shown to elicit CTL, T helper and antibody responses in a variety of animal models [4-8]. However, DNA vaccines alone stimulated only weak T-cell responses in monkeys [9] and humans [10]. To enhance antigen expression levels, various viral vector vaccines have been explored. For example, antigens expressing viral vectors based on poxviruses or adenoviruses were shown to be potent inducers of antigen-specific immune responses in SIV/HIV vaccine studies $[9,11]$. In addition to increased expression levels, the triggering of innate immune responses by the viral vector particles also seems to contribute to the immunogenicity of viral vector vaccines. However, in contrast to DNA vaccines, repeated immunizations with the same viral vector vaccine appear to be limited by immune responses to the viral vector particles $[12,13]$. Thus, DNA prime viral vector boost regimens are considered to be one of the most promising strategies to induce long-lasting CTL responses in humans $[9,14,15]$.

In addition to prime-boost regimens, a variety of adjuvants including immunomodulatory cytokines such as GM-CSF [16-22] were explored to improve the efficacy of DNA vaccines.

GM-CSF expression plasmids were co-injected with plasmids encoding vaccine antigens to examine the adjuvant activity in mouse models for HIV-1 [17-19], Hepatitis C virus [20,21] and HSV-2 [22] infection. Coexpression of GM-CSF enhanced antigen-specific T-cell proliferation and humoral immune responses, but had little effect on CTL responses. Over-expression of GM-CSF at the injection site led to the increased recruitment of macrophages and dendritic cells (DCs) $[23,24]$ and influenced the activation status of antigen-presenting cells (APCs) [25]. The temporal and spatial co-expression of antigens and GMCSF seems to be critical for optimal T-cell priming [26]. In addition, the fusion proteins of antigens and GM-CSF [27] and DNA vaccines encoding such fusion proteins $[28,29]$ were shown to improve antigen-specific antibody responses and cancer immunotherapy. The covalent linkage of the antigen and GM-CSF might allow the targeting of APCs expressing GM-CSF receptors, such as DCs. This could improve antigen uptake and presentation and thus also enhance CD8 $\mathrm{T}$ cell responses, similar to targeting strategies based on the macrophage mannose receptor or the DEC205 receptor [30,31]. Therefore, we compared the antigen-specific CD8 T-cell responses induced by DNA vaccines encoding GM-CSF ovalbumin fusion proteins (GM-OVA) with those raised by DNA vaccines coexpressing GM-CSF and ovalbumin (OVA) as two unlinked proteins. Since the antigen expression levels of, and the innate response to, DNA and viral vector vaccines differ considerably, the effect of GM-CSF was determined in DNA immunizations and DNA prime adenoviral vector boost regimens. Surprisingly, immunization with genetic vaccines encoding the GM-CSF ovalbumin fusion protein suppressed CD8+ T cell responses, while coexpression of GM-CSF was found to be a potent stimulator of antigenspecific CD8+ T cell responses. Induction of autoantibodies neutralizing GM-CSF by genetic vaccines encoding the fusion-protein, but not those coexpressing GM-CSF and OVA, might explain the varying effects observed.

\section{Results \\ DNA and adenoviral vector vaccines}

The expression plasmid encoding the fusion protein of GM-CSF and ovalbumin (GM-OVA) was generated by cloning the murine GM-CSF CDNA, a flexible linker, the OVA cDNA and a $\mathrm{HIS}_{6}$-tag as a single open reading frame into pcDNA3.1 (Fig. 1A). Three control plasmids expressing ovalbumin alone (OVA), ovalbumin fused to the leader peptide of GM-CSF ( $\triangle \mathrm{GM}$-OVA), or ovalbumin fused to the open reading frame of rhesus monkey GMCSF (GM $\left.{ }^{\text {rh }}-\mathrm{OVA}\right)$, which is biologically inactive in murine cells, were also constructed. Coexpression of murine GMCSF and OVA from the same plasmid was achieved by a modified bidirectional promoter based on the immediate early gene of human cytomegalovirus (GM-DP-OVA). After transient transfection into 293T cells, expression of the recombinant proteins was detected in cell supernatants by Western Blot analysis. The OVA plasmid and the $\triangle \mathrm{GM}$-OVA plasmid expressed a protein of $50 \mathrm{kD}$, which corresponds to the size of ovalbumin, whereas both fusion proteins migrate at a size of about $75 \mathrm{kD}$ (Fig 1B). The expression levels of the plasmids encoding the fusion proteins were slightly higher than those obtained with OVA and $\triangle \mathrm{GM}-\mathrm{OVA}$, whereas the expression of ovalbumin from the GM-DP-OVA plasmid is reduced substantially, probably due to a lower activity of the bidirectional promoter. GM-DP-OVA lacks the C-terminal tag explaining the slightly lower size of the protein in the Western blot (Fig. 1B). For further in vitro characterization of GMOVA, the protein was purified from transfection supernatants via $\mathrm{Ni}^{2+} \mathrm{NTA}$ agarose beads. Using a GM-CSFdependent cell line, comparable bioactivity was observed for GM-OVA and control supernatants from a GM-CSF producer cell line (data not shown). Adenoviral vectors containing the expression cassettes GM-OVA, GM-DPOVA, $\mathrm{GM}^{\text {rh }}$-OVA or $\triangle \mathrm{GM}$-OVA were constructed using the pAd-Easy system. Expression of the transgenes and GMCSF bioactivity was confirmed for the adenoviral vectors after infection of 293 cells. The relative expression levels 
A

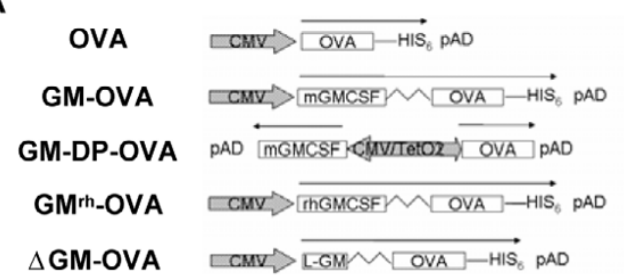

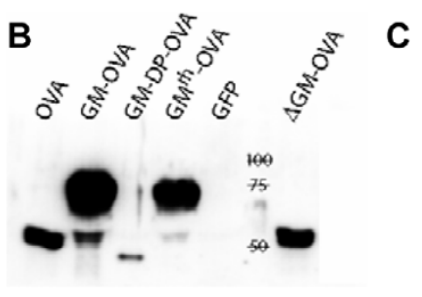

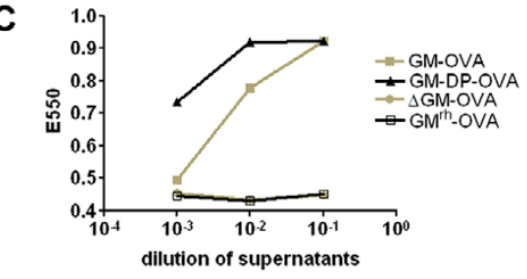

Figure I

Map and characterization of vaccine constructs. (A) Expression cassettes of the indicated vaccine constructs are shown. All open reading frames are under the control of the human cytomegalovirus immediate early promoter (CMV) or its derivative (CMVtetO2). His : C-terminal tag; L-GM: leader peptide of GM-CSF; m: murine; rh: rhesus monkey; "

[Gly4Ser] ${ }^{3}$-linker. (B) Ovalbumin-specific Western Blot analysis of supernatants of 293T cells transiently transfected with plasmids containing the indicated expression cassettes. GFP: supernatant of cells transfected with a GFP expression plasmid. (C) GM-CSF dependent FDCP-I proliferation. 293 cells were infected with adenoviral vectors containing the indicated expression cassettes and the GM-CSF levels in the supernatants were determined $24 \mathrm{~h}$ post infection. Serial dilutions of the supernatants were co-cultured with FDCP-I cells for 2 days. Proliferation was measured by a MTT assay.

of OVA by the different adenoviral vector constructs mirrored those observed after transient transfections of the corresponding plasmid DNAs (data not shown). To compare the expression levels of GM-CSF, serial dilutions of the supernatants of 293 cells infected with the adenoviral vectors were tested in a proliferation assay with a GM-CSFdependent cell line (Fig 1C.) In contrast to the OVA expression levels, the bicistronic vector expressed slightly higher levels of bioactive GM-CSF in comparison to the vector encoding the GM-OVA fusion protein. The supernatants of cells infected with adenoviral vectors enoding $\mathrm{GM}^{\text {rh }}$-OVA or $\triangle \mathrm{GM}$-OVA did not induce proliferation of the GM-CSF-dependent murine cell line. Since $\mathrm{GM}^{\mathrm{rh}}$-OVA has GM-CSF activity on human cells (data not shown), rhesus monkey GM-CSF is not bioactive on murine cells.

\section{Influence of the GM-CSF fusion protein on dendritic cell differentiation and antigen presentation}

GM-CSF plays a critical role in the differentiation of dendritic cells. Bone marrow derived monocytes (BMDM) can be differentiated into immature DCs by co-culture with GM-CSF and IL-4. The ability of purified GM-OVA to generate DCs was therefore compared to recombinant GMCSF. Recombinant GM-CSF and GM-OVA were equally efficient in generating immature DC (low CD80, CD83, CD86) from BMDMs. To a similar extent, the immature DCs induced by GM-OVA or recombinant GM-CSF could be matured by LPS as evidenced by the upregulation of costimulatory molecules (Fig 2A). To test whether the fusion of GM-CSF to ovalbumin enhances the activation of antigen-specific CD8 $+\mathrm{T}$ cells by antigen-presenting cells (APC), splenocytes from T-cell receptor transgenic OT-I mice were labeled with CFSE and cultured in the presence of decreasing concentrations of GM-OVA or ovalbumin for four days. The proliferation-dependent decrease in
CFSE fluorescence of CD8+ T-cells was analyzed by FACS. GM-OVA induced proliferation of OT-I cells at 10-fold lower concentrations than ovalbumin (Fig 2B). The addition of recombinant GM-CSF to ovalbumin-containing cultures did not enhance proliferation of OT-I cells (data not shown), suggesting that the fusion protein enhances presentation of ovalbumin peptides most likely by GMCSF receptor positive APCs.

\section{CD8+ $T$ cell responses after immunization with gene-based vaccines encoding the GM-CSF fusion protein}

Since the GM-OVA fusion protein maintained GM-CSF bioactivity and enhanced the proliferation of OVA-specific CD8+ T cells in cell culture, we expressed the GMOVA fusion protein by DNA and adenoviral vectors in vivo and determined ovalbumin-specific CD8+ $\mathrm{T}$ cell responses. C57BL6 mice were either immunized by one or two (week 0 and 5) DNA injections (-/D and D/D), a single adenoviral vector injection (-/A) or a DNA prime (week 0) and adenoviral vector boost (week 5) regimen (D/A). The DNA and adenoviral vectors either encoded the GM-OVA fusion protein or ovalbumin. One week after the first or second immunization, OVA-specific CD8 + T cell responses were determined using SIINFEKL/ $\mathrm{H} 2-\mathrm{K}^{\mathrm{b}}$ tetramers. The functional activity of OVA-specific CD8+ T cells was assessed by stimulation with the SIINFEKL peptide followed by staining for interferon- $\gamma$ and the degranulation marker CD107a [32]. A single injection of DNA encoding either OVA or GM-OVA did not result in any detectable CD8+ T cell responses, while a single adenoviral vector immunization with either antigen resulted in similar levels of tetramer-positive and IFN- $\gamma / \mathrm{CD} 107$ a double positive CD $8+\mathrm{T}$ cells, with approximately $6 \%$ of the total CD8+ T cells being specific for the SIINFEKL peptide. After two injections of the OVA DNA vaccine, OVA- 
A

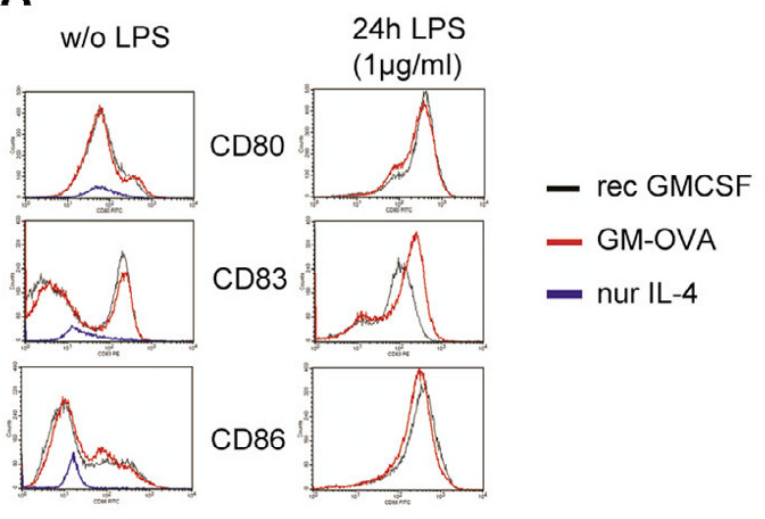

B

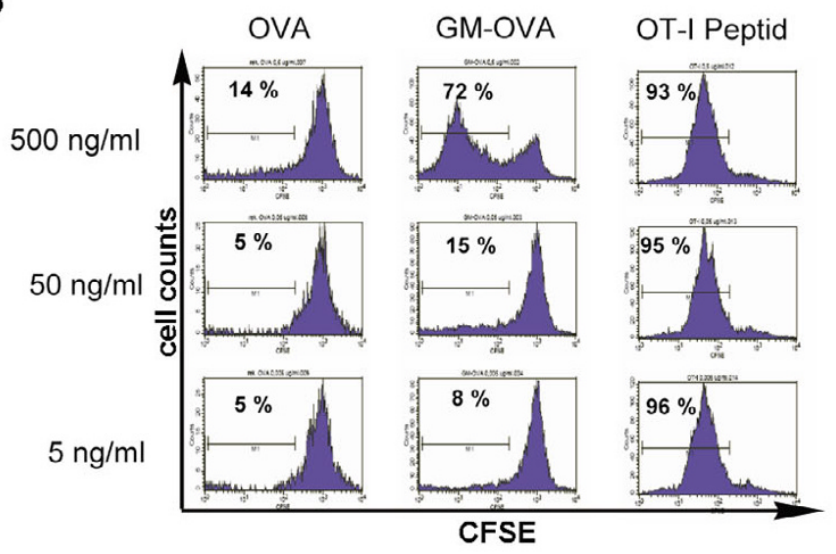

Figure 2

Influence of GM-OVA on the generation of DC (A) and stimulation of OT-I specific T-cells (B). A) BM-derived monocytes were cultured for 8 days in the presence of GM-OVA or recombinant GM-CSF (5 ng/ml each) and IL-4 (I ng/ml). The CDI l c+ cells were analysed for the expression of CD80, CD83, and CD86 surface markers before (left panel) and after addition of LPS (right panel). B) Splenocytes of TCR-transgenic OT-I mice were labelled with CFSE and incubated for $72 \mathrm{~h}$ in the presence of either ovalbumin, GM-OVA or OT-I peptide at the indicated final concentration. The addition of recombinant GM-CSF and ovalbumin as separate proteins did not induce proliferation (data not shown).

specific CD8+ $\mathrm{T}$ cells became detectable constituting approximately $0.4 \%$ of the CD $8+$ T cells. Two injections of GM-OVA DNA did not result in detectable levels $(>0.1 \%)$ of OVA-specific CD8 $+\mathrm{T}$ cells demonstrating reduced CD8+ T cell responses for the GM-CSF ovalbumin fusion protein. Significantly reduced $\mathrm{CD} 8+\mathrm{T}$ cell responses could also be observed for the GM-OVA fusion protein in the DNA prime adenoviral vector boost immunization. The mean percentage of tetramer positive CD8+ T-cells decreased to $5,5 \%$ in the GM-OVA group compared to $13,8 \%$ of tetramer positive cells in animals immunized with the vaccines only expressing ovalbumin (Fig 3A). Results for the CD107a/IFN- $\gamma$ staining paralleled the results obtained with the tetramers (Fig. 3B). Priming with the OVA DNA vaccine clearly enhanced CD8+ T cell responses after the adenoviral vector immunization. In contrast, CD8+ T cell responses after the adenoviral GMOVA boost were not enhanced by priming with GM-OVA DNA (Fig 3A, B).

\section{Humoral immune responses after immunization with gene- based vaccines encoding the GM-CSF fusion protein}

Since the fusion of GM-CSF to antigens has previously been shown to enhance humoral immune responses to the antigens, we also studied the effect of GM-OVA on OVA-specific IgG1 and IgG2a antibody levels. Since a single injection of the DNA and adenoviral vector vaccines encoding either GM-OVA or OVA did not result in detectable antibody levels, only the results for two repeated DNA injections and the DNA prime adenoviral vector boost regimen are shown (Fig. 4). Strikingly, mice immu- nized with GM-OVA by DNA or DNA plus adenoviral boost did not produce any detectable levels of ovalbuminspecific IgG2a antibodies. In contrast, immunization with vaccines encoding only ovalbumin resulted in readily detectable levels of antigen-specific IgG2a antibodies (Fig. 4B). Opposite effects were observed on ovalbumin-specific IgG1 antibody levels. These were significantly elevated for the GM-OVA groups in comparison to the groups immunized with the ovalbumin-expressing vaccines (Fig. 4A).

\section{Stimulation of CD8+ $T$ cell responses by vaccines coexpressing GM-CSF and ovalbumin}

Suppression of CD8+ T cell responses by the GM-OVA vaccines could be directly due to the bioactivity of GMCSF. If this were the case, the coexpression of GM-CSF and ovalbumin from bicistronic expression cassettes should also suppress CD8+ T cell responses. However, the opposite effect was observed. Despite substantially lower ovalbumin expression levels by the GM-DP-OVA vaccines coexpressing GM-CSF and ovalbumin, DNA prime adenoviral vector boost immunization with GM-DP-OVA vaccines enhanced the percentage of SIINFEKL-specific CD8+ $\mathrm{T}$ cells compared to vaccines only expressing ovalbumin (Fig 5, left column). This is in sharp contrast to the results obtained after GM-OVA vaccination, which reduced the percentage of tetramer positive CD8+ cells.

After immunization with the bicistronic vaccines more than a quarter of all CD8+ cells were specific for ovalbumin. Given this extraordinarily high CD8+ T cell response, 
A

B
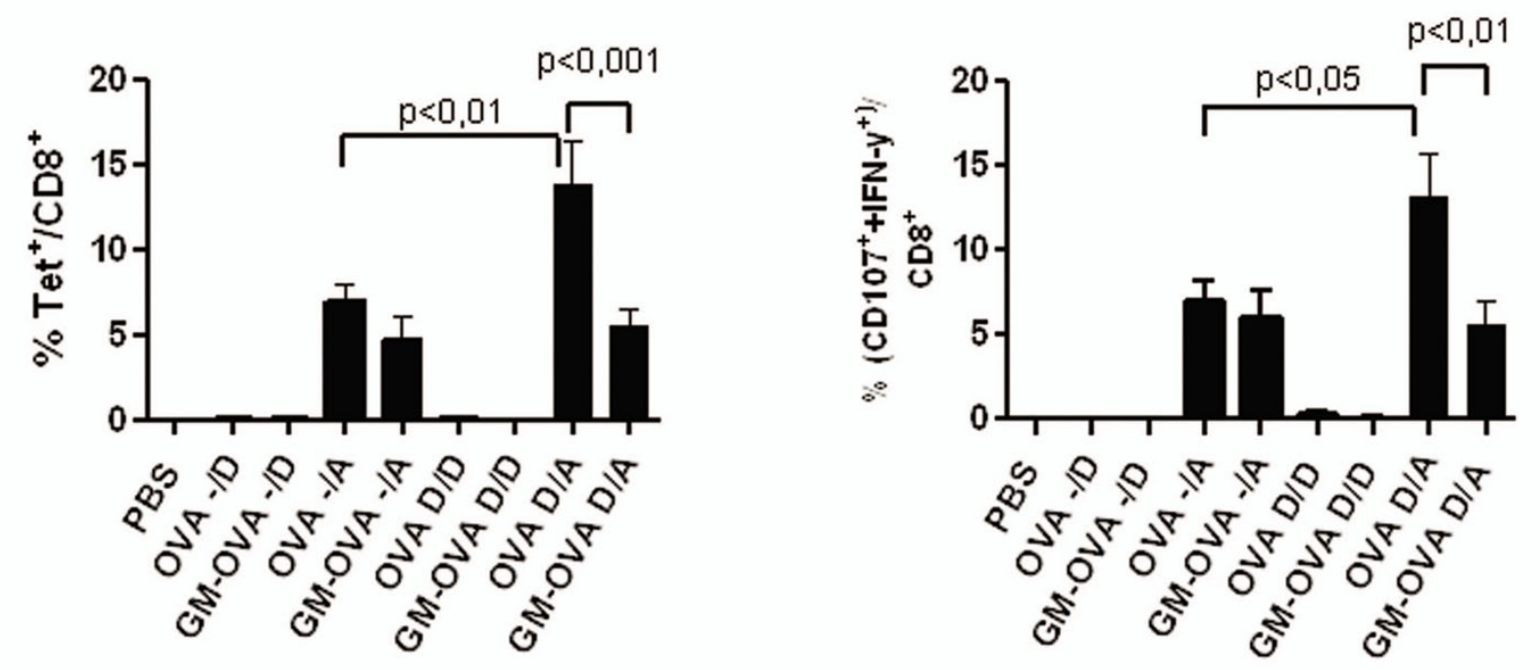

Figure 3

Prime-boost regimens of GM-OVA suppress OVA-specific CD8+ immune responses. Mice were immunized by one DNA (-/D), one adenoviral vector (-/A), two DNA (D/D), or a DNA prime adenoviral vector boost (D/A) injection. The DNA and adenoviral vector either encoded ovalbumin (OVA) or the GM-CSF-ovalbumin fusion protein (GM-OVA). One week after a single injection or the second injection the percentage of OT-I tetramer positive CD8 ${ }^{+}$cells (A) and IFN- $\gamma$ and CDI07a double-positive CD8+ cells after stimulation with the OT-I peptide (B) were determined. All percentages are percent of CD8+ lymphocytes. Mean percentages with SEM of three independent experiments each with three animals per group are shown. Only statistically significant differences between immunization regimens expressing ovalbumin or GM-OVA in the one-way ANOVA test are indicated.

the OVA-specific cells were further characterized functionally. Stimulation of the spleen cells of mice immunized with the bicistronic vaccine with the SIINFEKL peptide also resulted in more than $25 \%$ IFN- $\gamma$ positive CD $8+$ cells. Most of IFN- $\gamma$ positive cells also displayed cytotoxic activity as indicated by costaining with the CD107a degranulation marker (Fig 5, center column). In addition, the coexpression of GM-CSF enhanced the percentage of IFN$\gamma$ and interleukin 2 double-positive cells after peptide stimulation, confirming the polyfunctional nature of the CD8+ T cell responses induced by this potent immunization regimen (Fig 5, right column). About 90\% of all tetramer-positive CD8 cells also showed the downregulation of CD62L expression (Fig 6), which further indicates an effector phenotype [33,34]. No qualitative differences among the various immunization groups were detectable, suggesting that GM-CSF only influences the quantity but not the functional properties of the vaccine-induced CD8+ T-cells.

\section{CD8 $T$ cell responses induced by vaccines encoding a biologically inactive GM-CSF ovalbumin fusion protein}

In contrast to the GM-OVA vaccines, the coexpression of GM-CSF and ovalbumin did not suppress CD8 T cell responses. This indicates that the suppressive effects of GM-OVA vaccines on the CD8 $\mathrm{T}$ cell responses are not simply due to the biological activity of GM-CSF. To exclude the possibility that immune responses were affected by altered antigen expression levels, subcellular localization, and/or stability of the fusion protein, mice were also immunized with DNA and adenoviral vector vaccines expressing a fusion protein of rhesus macaque GM-CSF and ovalbumin. Although fully active on primate cells, rhesus monkey GM-CSF was inactive in rodent cells (Fig. 1C). In all parameters investigated, including Tetramer analyses and intracellular staining for IFN- $\gamma$, interleukin 2, and/or CD107a, the immune response induced by the rhesus monkey GM-OVA vaccines did not differ significantly from the response induced by the OVA vaccines (Fig. 5 and 6).

\section{Antibody responses induced by gene-based vaccines encoding bioinactive GM-CSF fusion protein or coexpressing GM-CSF and ovalbumin}

The GM-OVA vaccines not only suppressed cellular immune responses but also the antigen-specific IgG2a antibody response (Fig 4B). Therefore, ovalbumin-specific antibody levels of the IgG1 and IgG2a subtype were 

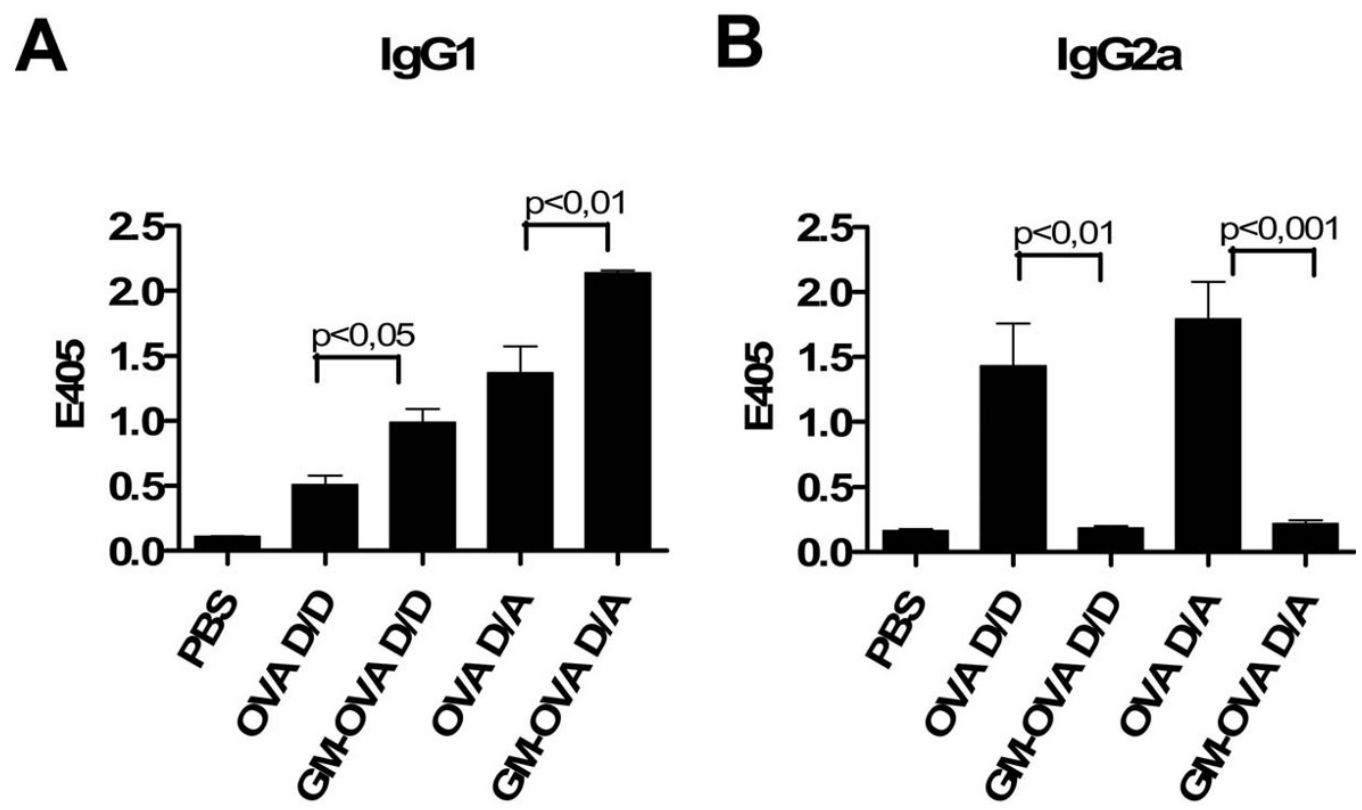

Figure 4

GM-OVA alters the humoral immune response. Mice were immunized as described in figure legend 3. Ovalbumin-specific IgGI (A) and IgG2a (B) antibodies were determined by ELISA. Shown are the mean $\mathrm{OD}_{405}$ values with their SEM ( $\mathrm{n}=6$ ) from the vaccinated animals. Immune sera were diluted I to 10 and I to 1000 for the determination of IgG2a and IgG I antibody levels, respectively. Only statistically significant differences between immunization regimens expressing either ovalbumin or GM-OVA in the one-way ANOVA test are indicated.

also determined for the vaccines coexpressing GM-CSF and ovalbumin or expressing the fusion protein of inactive rhesus GM-CSF and ovalbumin. Vaccinations with GM-OVA again suppressed OVA specific IgG2a antibody responses in comparison to the vaccine expressing only ovalbumin (Fig. 7). In contrast, the coexpression of GMCSF or the expression of the fusion proteins of rhesus monkey GM-CSF and ovalbumin did not affect IgG1 and IgG2a antibody levels in the DNA prime adenoviral vector boost immunization regimen.

\section{Induction of neutralizing antibodies to GM-CSF}

Whereas CD8 T cell responses upon injection of the AdOVA vaccine were significantly increased in DNA-OVA primed mice, such a priming effect was not observed with the DNA-GM-OVA prime and Ad-GM-OVA boost regimen (Fig. 3), suggesting that immune responses elicited by priming with DNA-GM-OVA might have suppressed the secondary response. Since neutralizing antibodies to GMCSF have been observed previously after injection of recombinant GM-CSF proteins $[35,36]$, we analysed sera from immunized mice for the presence of GM-CSF neutralizing antibodies using the GM-CSF-dependent FDCP1 cells. While the sera of mice immunized with the GMOVA vaccines inhibited GM-CSF-dependent cell growth down to a 1:100 dilution, no inhibitory activity on FDCP-
1 cells was observed for the sera of mice immunized with vaccines coexpressing GM-CSF and OVA or expressing the monkey GM-CSF ovalbumin fusion proteins (Fig. 8). Consistently, autoantibodies binding to GM-CSF in an ELISA were only detected in mice immunized with vaccines encoding the fusion proteins, but not in any of the other vaccine groups (data not shown).

\section{Influence of neutralizing antibodies to GM-CSF on immune responses and viral replication in a retroviral infection model}

Since GM-CSF knock-out mice had an impaired CD8+ T cell response after immunization with peptides [37], we determined the relevance of neutralizing anti-GM-CSF antibodies induced by immunization with the GM-OVA vaccine, in the Friend-Virus (FV) infection model. Immunological control of FV infection was shown to be dependent on antibodies and CD4+, and CD8+ T-cell responses $[38,39]$. To induce neutralizing GM-CSF antibodies mice were primed with the DNA and boosted with the adenoviral vector vaccine, both expressing GM-OVA. As controls, mice were immunized against OVA with vaccines expressing either ovalbumin alone or GM-CSF and ovalbumin from a bicistronic expression cassette. One week after the adenoviral vector boost, neutralizing antibodies were detected in all animals immunized with the GM- 
A

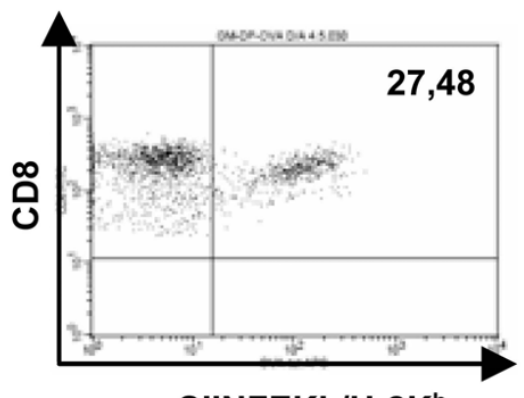

SIINFEKL/H-2K ${ }^{b}$

B

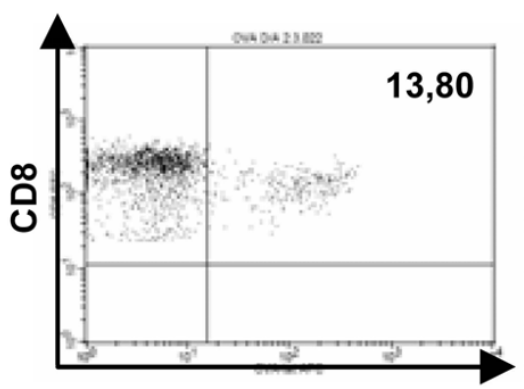

SIINFEKL/H-2K ${ }^{b}$

C

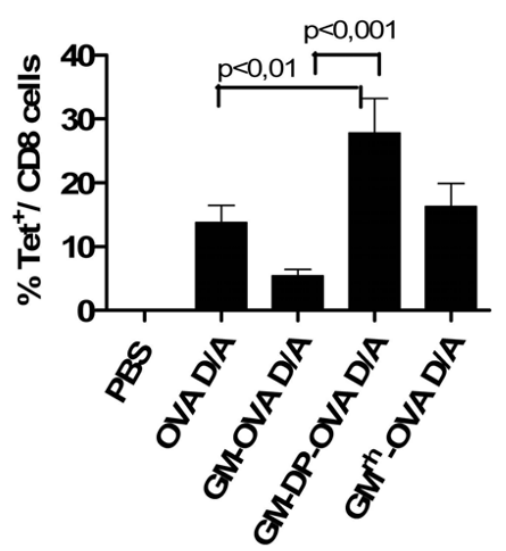

GM-DP-OVA D/A

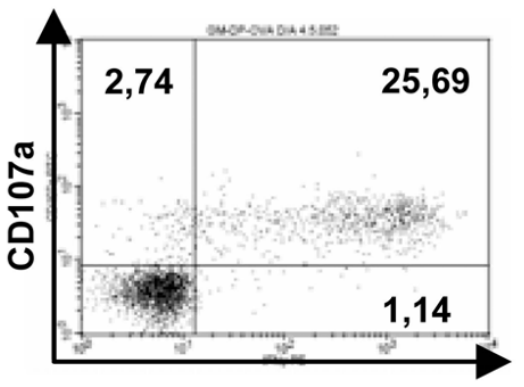

IFN-y

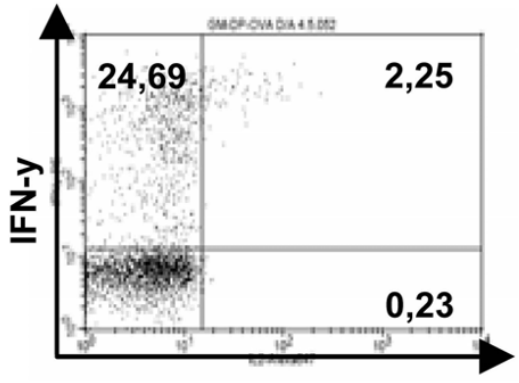

IL-2
OVA D/A

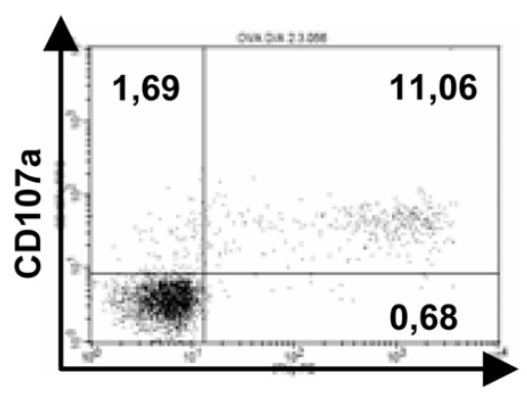

IFN-y

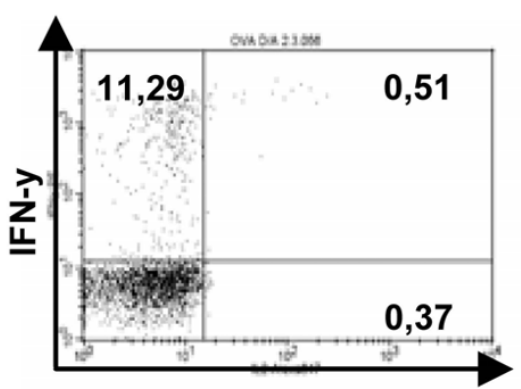

IL-2
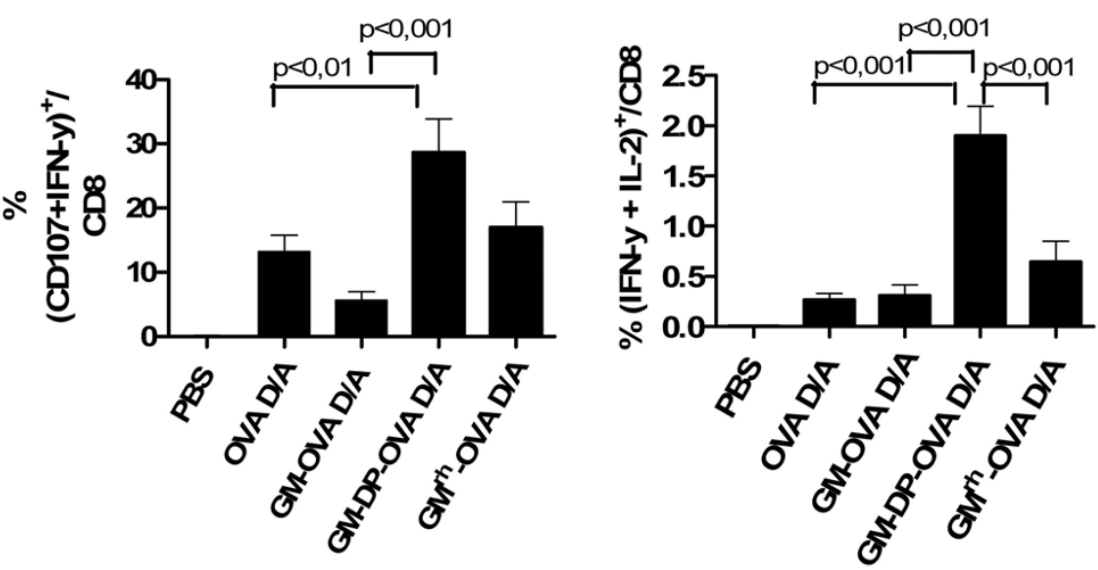

Figure 5

Coexpression of GM-CSF and ovalbumin enhances CD8+ immune responses. Mice were immunized by the DNA prime adenoviral vector boost as described in figure legend 3 with the DNA and adenoviral vectors encoding the indicated expression cassettes (s. Fig. IA). Representative dot blots for SIINFEKL tetramer staining (left column), CDI07 and IFN- $\gamma$ staining (center column) and IFN- $\gamma$ and IL-2 staining (right column) of CD8+ lymphocytes obtained from individual mice immunized with GM-DP-OVA (A) and OVA (B) are shown. Panel $C$ gives the mean and SEM for the immunization groups indicated and the parameters analysed. Only statistically significant differences between the groups are indicated. Three independent immunization experiments with three animals per group were performed for the PBS, OVA, and GM-OVA groups, while one experiment was performed with a total of 6 mice for the GM-DP-OVA and the GMrh-OVA groups. 
A

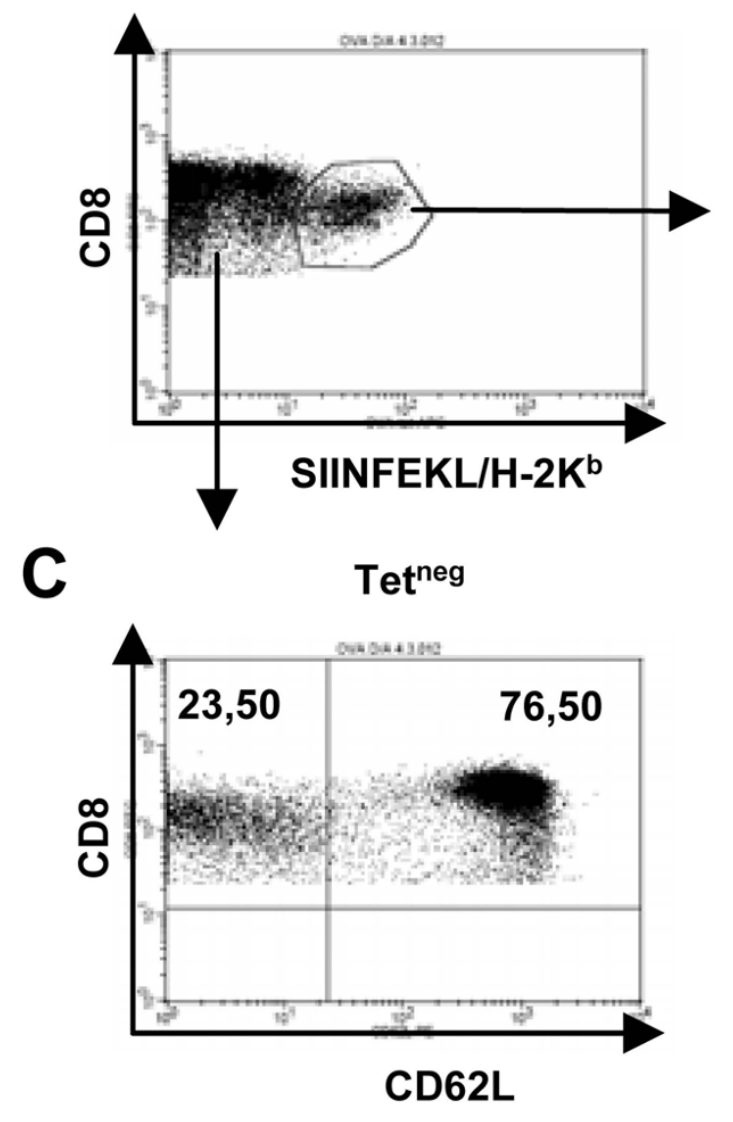

B
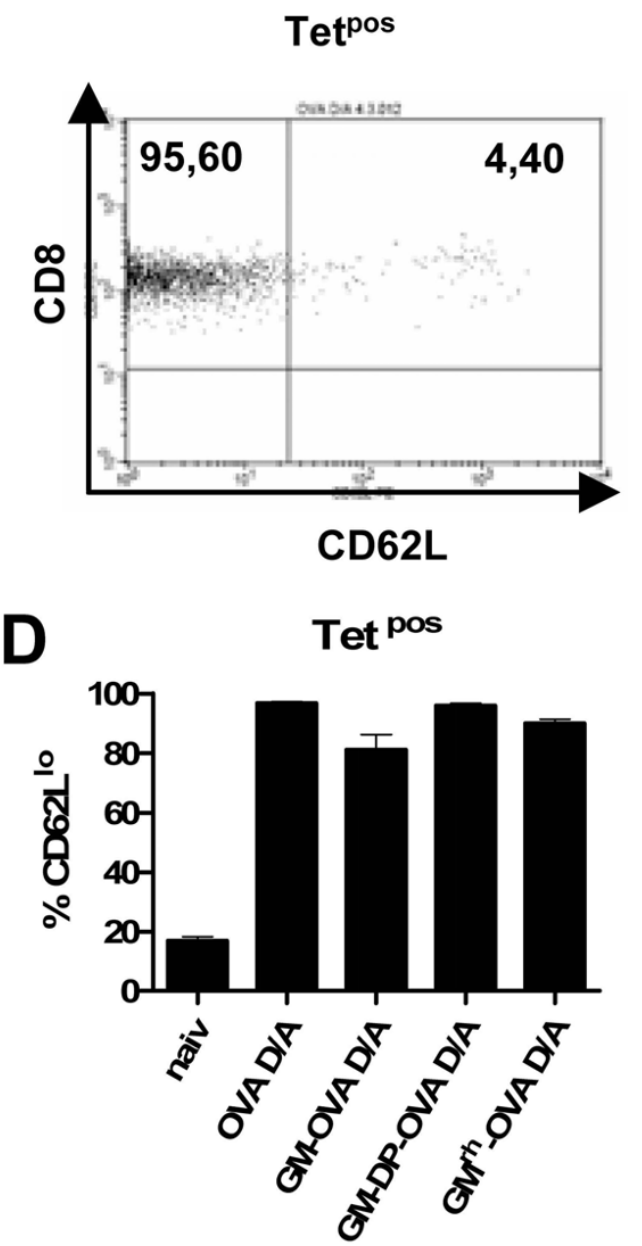

\section{Figure 6}

GM-CSF does not influence the activation status of CD8+ lymphocytes. Mice were immunized as described in figure legend 5. The effector phenotype of the antigen-specific CD8+ cells was confirmed by costaining for CD8, SIINFEKL/H-2Kb, and CD62L. CD8 and Tetramer double positive cells were gated (A) and analysed for CD62L expression (B, D). D) Mean percentage and SEM of CD62L-low cells from the CD8 and Tetramer double positive cells from three mice per group are shown. Panel C gives a representative example of CD62L expression levels of the CD8+, but tetramer negative population.

OVA vaccines, but not in any of the other groups. The antibodies remained detectable during the whole observation period (data not shown). Induction of virus-specific $\mathrm{CD} 8+$ and $\mathrm{CD} 4+\mathrm{T}$ cell responses was determined by MHC-I and MHC-II tetramer staining 11 days post challenge with FV. Similar levels of antigen-specific CD4+ and CD8+ T cell responses were observed in all immunized groups (Fig. 9A,C). In addition, FV loads in the blood and the spleen were not affected notably by the type of vaccine antigen (Fig. 9B,D). Thus vaccine-induced neutralizing antibodies against GM-CSF neither influenced $\mathrm{T}$ cell responses nor viral load after FV infection. Interestingly, all immunized groups had significantly reduced numbers of FV-specific CD8+-T-cells compared to the non-immunized control animals (Fig. 9A), suggesting some interference between vaccine-induced immune responses and antiviral CD8+ $\mathrm{T}$ cell responses after FV infection.

\section{Discussion}

A side-by-side comparison of a DNA prime adenoviral vector boost immunization regimen leading either to the expression of a fusion protein of GM-CSF and the model antigen or to the coexpression of GM-CSF and antigens as two separate proteins revealed striking differences in the induction of polyfunctional antigen-specific CD8 + T cell responses and humoral immune responses. Immuniza- 

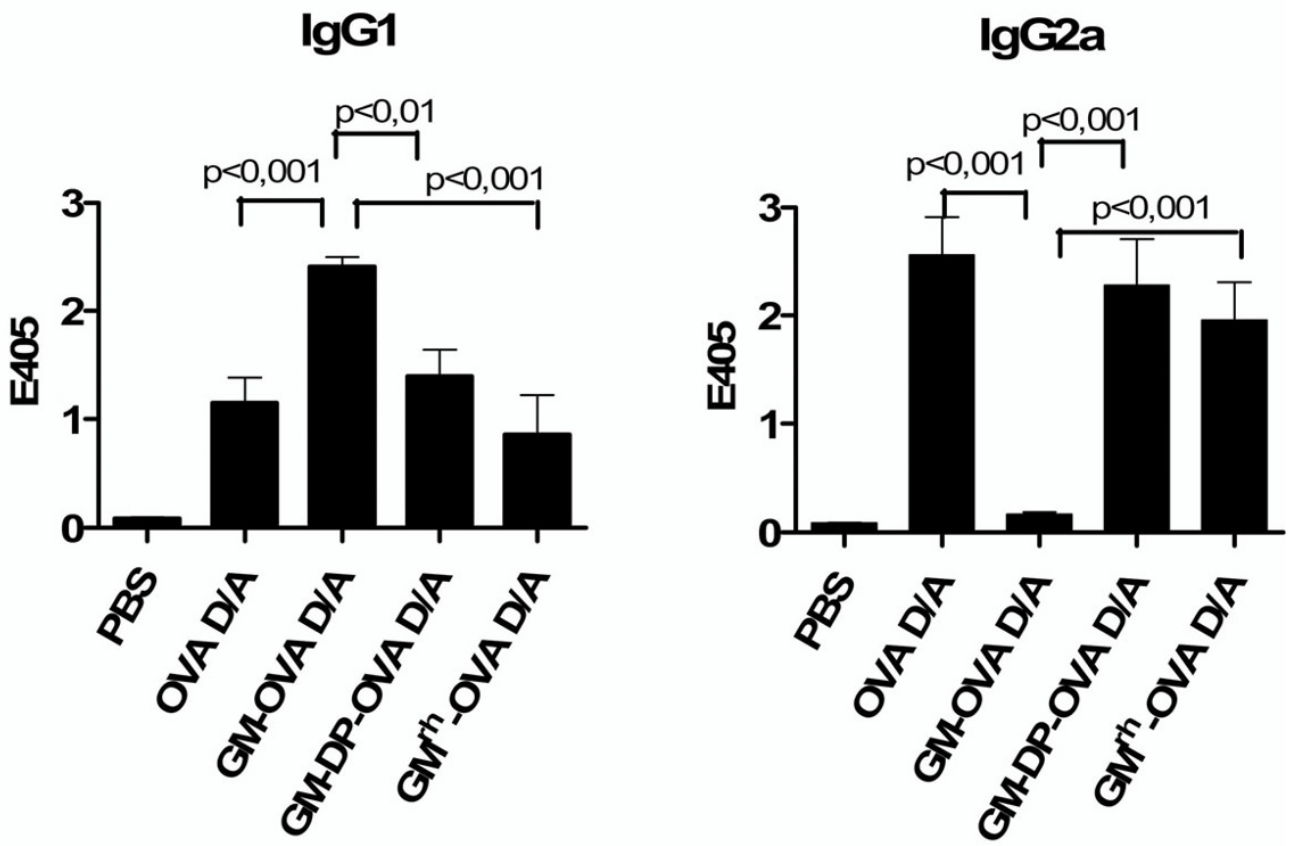

Figure 7

Coexpression of GM-CSF and ovalbumin does not bias the humoral immune response. Mice were immunized by DNA prime adenoviral vector boost injections as described in figure legend 5. Ovalbumin-specific $\lg G I(A)$ and $\lg G 2 \mathrm{a}(\mathrm{B})$ antibodies were determined by ELISA. Shown are the mean $\mathrm{OD}_{405}$ values with their SEM $(n=6)$ from the vaccinated animals. Immune sera were diluted I to 10 and I to 1000 for determination of IgG2a and IgGI antibody levels, respectively. Only statistically significant differences between immunization regimens expressing either ovalbumin or GM-OVA in the one-way ANOVA test are indicated.

tion with gene-based vaccines encoding the bioactive GMCSF antigen fusion proteins suppressed CD8+ $\mathrm{T}$ cell responses, while the coexpression of GM-CSF and antigens stimulated these responses. Although the fusion proteins enhanced the stimulation of antigen-specific CD8+ $\mathrm{T}$ cells in coculture experiments with antigen-presenting cells, the induction of neutralizing antibodies to GM-CSF probably counteracted any beneficial effect of the fusion protein on the enhancement of antigen uptake or presentation in vivo. the injection of recombinant GM-CSF proteins or GM-CSF fusion proteins has been shown previously to induce antibodies to GM-CSF in mice and humans $[29,35,36,40]$. Differences in postranslational modifications such as glycosylation patterns between the recombinant proteins and the endogenously expressed GM-CSF have been postulated to be responsible for this loss of tolerance $[35,40]$. Since the GM-CSF expression levels after infection with the bicistronic vector was the same or even higher when compared to the GM-OVA encoding vector, we can exclude that simple overexpression of the cytokine is a reason for the break of tolerance. However, the induction of GM-CSF neutralizing antibodies by genetic vaccines expressing GM-CSF antigen fusion proteins in the vaccinees suggests an alternative mechanism for this autoimmune response. B-cells with antigen receptor specificities for GM-CSF might take up the GMCSF-antigen fusion protein and present antigen-derived epitopes on MHC-II molecules. T-helper cells specific for the antigen part of the GM-CSF fusion protein could then stimulate these B-cells even in the absence of autoreactive GM-CSF-specific T-helper cells. This would be consistent with a previous hypothesis for the appearance of autoreactive antibodies [41] and with results from immunization studies with other fusion proteins $[42,43]$.

The consequences of neutralizing GM-CSF antibodies for the host are not well defined. Reconstitution of white blood cells after bone-marrow transplantation and immune responses to a protein vaccine were not impaired in the presence of GM-CSF autoantibodies [44]. Using the FV infection model, we did not observe any negative effects associated with GM-CSF autoantibodies either. Consistently, no pathological alterations have been reported to be associated with anti-GM-CSF antibodies in cancer patients. However, GM-CSF knock out mice were not able to generate CD8+ T cell responses after peptide 


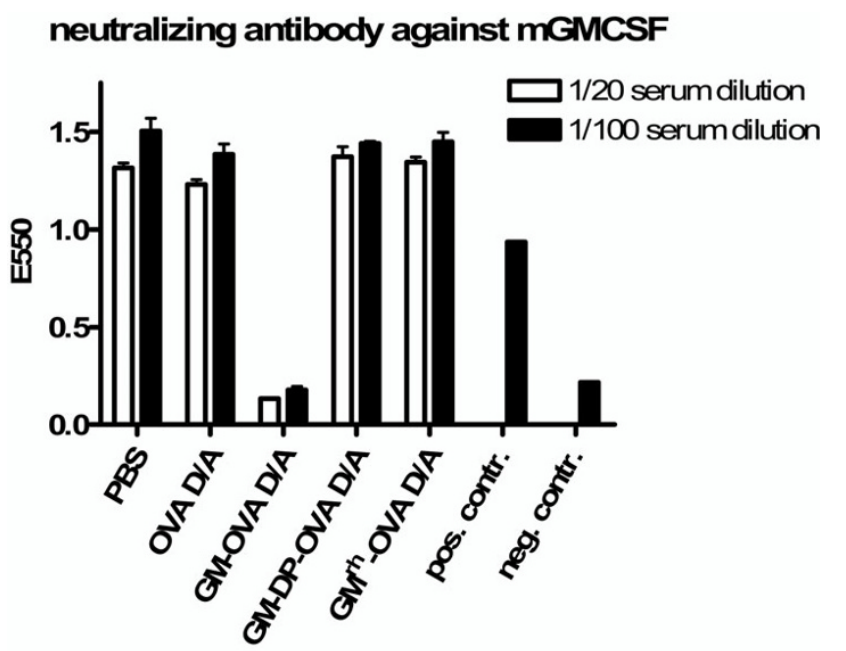

Figure 8

GM-OVA induces neutralizing antibodies against murine GM-CSF. Mice were immunized with the indicated DNA prime adenoviral vector boost regimens. One week after the adenoviral vector booster immunization, the GMCSF neutralizing activity was determined on the GM-CSF dependent FDCP-I cell line stimulated with 2,5 ng murine GM-CSF/ml). Mouse sera were tested in a I/20 (white bars) and a I/I00 (black bars) dilution. Medium without GM-CSF served as a negative control, whereas GM-CSF-containing medium without mouse serum was the positive control.

immunization and IgG2a antibody production was also reported to be delayed after protein immunization [37]. In the present study, induction of GM-CSF neutralizing antibodies coincided with suppression of CD8+ T cell responses induced by a DNA prime adenoviral vector boost regimen. Lack of suppression of $\mathrm{CD} 8+\mathrm{T}$ cell responses after a single immunization with the same DNA or adenoviral vector vaccine further supports a causal relationship between GM-CSF antibodies and suppression of $\mathrm{CD} 8+\mathrm{T}$ cell responses, since in these immunization experiments GM-CSF neutralizing antibodies are absent at the time point of T cell priming. Depending on the precise immunostimulatory pathways employed by a vaccine or pathogen, the requirement for GM-CSF might differ significantly, providing an explanation for the different observations made in the mouse models. Although there is no direct evidence of clinical complications so far, possible long-term consequences of the anti-GM-CSF responses, such as involvement in pulmonary alveolar proteinosis (PAP) $[45,46]$, are difficult to exclude. Given the loss of tolerance by other fusion proteins $[42,43]$ and the immunogenicity of genetic vaccines, a more general note of caution regarding the use of genetic vaccines encoding fusion proteins between host proteins and heterologous antigens might even be justified.
In contrast to immunization with genetic vaccines encoding the GM-CSF-antigen fusion proteins, which strongly suppressed IgG2a antibody responses, the coexpression of GM-CSF and antigens in the DNA prime adenoviral vector boost regimen did not modulate IgG1 and IgG2a antibody responses notably. This was unexpected, since repeated immunizations with adenoviral vectors coexpressing GM-CSF and the amyloid-beta protein by the intranasal route resulted in a Th2-type immune response [47]. In addition, the coexpression of GM-CSF and antigens in numerous DNA immunization studies increased antibody responses $[16,18,20-22]$. Since the bicistronic expression cassette in our study expresses lower amounts of ovalbumin than the vaccine encoding ovalbumin only, GM-CSF coexpression seems to compensate for the lower antigen expression levels in the sense that in the presence of GM-CSF a lower amount of antigen is needed to induce comparable humoral immune responses than in its absence. Previous studies also show that increased antigen levels correlate with increased antibody titers, but do not influence the dominant immunoglobulin subtype[48]. Thus, the difference in the IgG1/IgG2a ratio observed after immunization with the genetic vaccine encoding the GMCSF-Ova fusion protein does not seem to be simply due to GM-CSF receptor signalling, since this also occurs by the coexpression of GM-CSF. However, immunization with vaccines encoding rhesus monkey GM-CSF fused to ovalbumin did not lead to a change in the IgG1/IgG2a ratio either, although no differences were observed between the expression levels of the two GM-CSF fusion proteins. This indicates that the change in the antigen-specific IgG1/ IgG2a ratio observed after immunization with the fusion protein depends on the GM-CSF bioactivity of the fusion protein and the covalent linkage of GM-CSF with the antigen.

The immunomodulatory properties of GM-CSF could also differ substantially with the type of antigens, the route of immunization, and/or the type of genetic vaccine used. This also seems to apply to the effect of GM-CSF on CD8+ $T$ cell responses. Coexpression of GM-CSF and antigens by DNA vaccines was shown to stimulate $\mathrm{CD} 8+\mathrm{T}$ cell responses in some studies $[17,49]$ but not in others $[19,50]$. In the context of a DNA prime adenoviral vector boost regimen, we observed that GM-CSF was a strong stimulator of CD8+ T cell responses. Coexpression of GMCSF by the DNA and adenoviral vector vaccines enhanced the percentage of CD8+ T cells specific for the immunodominant epitope of the antigens from approximately $11 \%$ to more than $25 \%$ as determined by tetramer staining and intracellular IFN- $\gamma$ staining. Although we can not completely rule out that the different antigen expression levels influence the strength of immune response, it seems unlike that lower antigen levels induce stronger CTL responses. Rather, it has been reported that increased anti- 


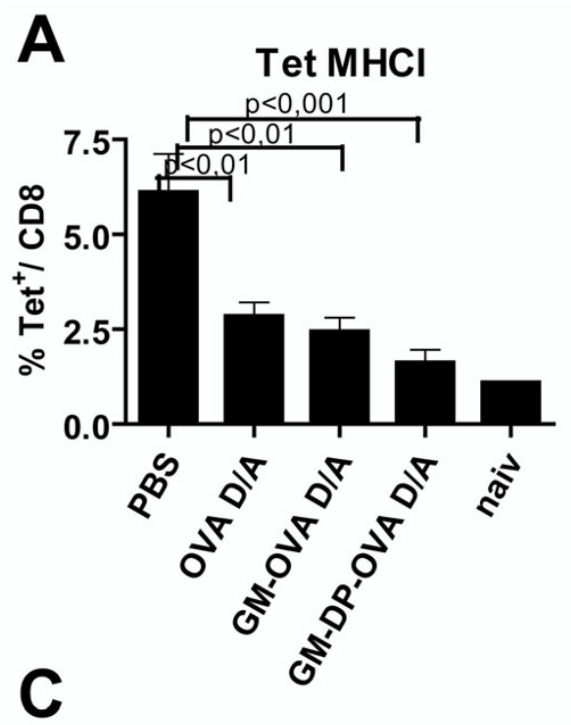

Tet MHC II

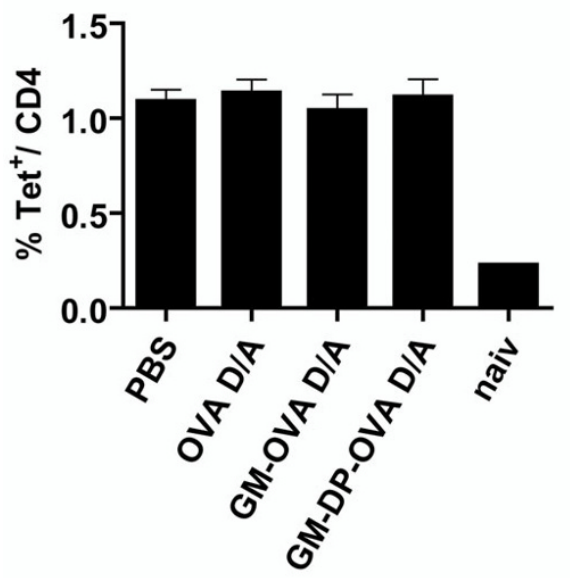

B

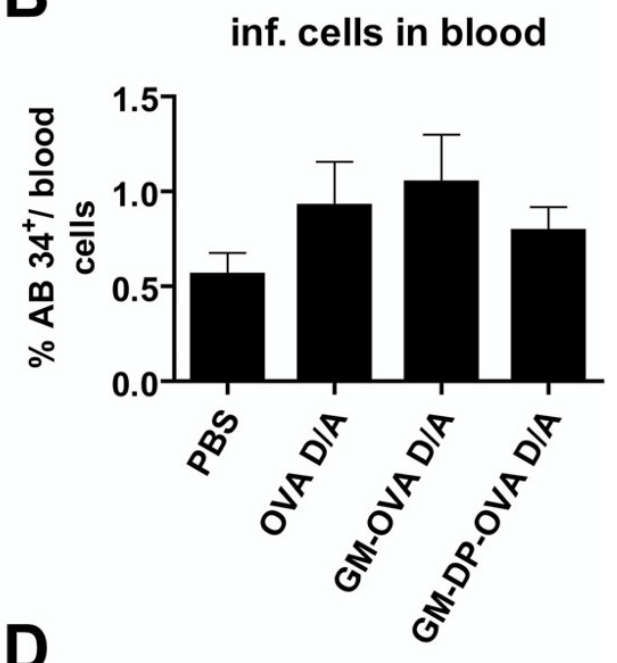

IC in spleen

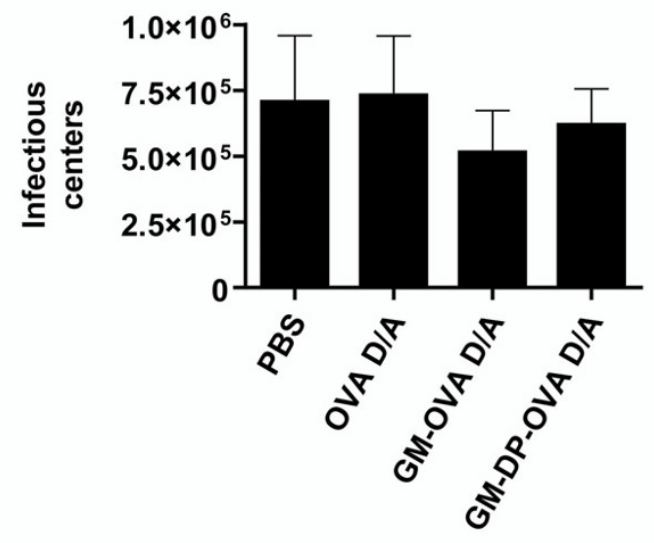

Figure 9

GM-CSF autoantibodies do not interfere with the control of FV infection. GM-CSF autoantibodies were induced by DNA prime adenoviral vector boost immunization with the GM-OVA vaccines. As controls, groups of mice were immunized with the OVA or the GM-DP-OVA vaccines, or were mock vaccinated (PBS). Two weeks after the adenoviral vector booster immunization, mice were challenged with 3000 SFFU of FV. I I days post challenge FV-specific immune responses were moni-

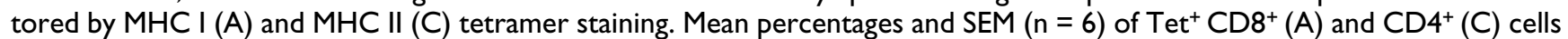
are shown. Splenocytes of an uninfected animal were used as negative control (naiv). The viral load in the blood was detected by $A B 34^{+}$cells via flow cytometry (B). In addition the numbers of infectious centers per spleen were determined (D).

gen expression levels obtained by codon-optimization or enhanced promotor activities correlate with the better induction of IFN- $\gamma$ producing T-cells or cytotoxic T-cells $[48,51]$.

Coexpression of GM-CSF and ovalbumin by DNA prime adenoviral vector boost immunizations led to a strong CD8 $+\mathrm{T}$ cell response, with more than a quarter of all CD8+ T cells being specific for a single immunodominant peptide. Although the percentage of CD8+ T cell specific for other antigens might well be lower than those obtained in the present study with the ovalbumin model antigens, the enhancement of CD8+ T cells responses by GM-CSF is encouraging. The antigen-specific CD8+ T cells induced in the presence of GM-CSF were not only numerous, but also displayed markers of polyfunctional $\mathrm{T}$ cells such as the coexpression of IFN- $\gamma$, IL-2, and the CD107a degranulation marker. T cells that produce both IFN- $\gamma$ and IL-2 were recently proposed to be important in the control of chronic viral infections, like CMV, EBV or in HIV LTNP and might be indicative of long-lived memory T-cells [52]. Although the functional relevance of the CD8+ T cell 
response induced by DNA and adenoviral vector vaccines coexpressing GM-CSF and antigens needs to be confirmed in relevant tumor and infection models, GM-CSF should be considered as a CD8+ T-cell adjuvant in DNA prime adenoviral vector immunization regimens.

\section{Conclusion}

Genetic vaccines encoding fusion proteins between antigens and a host protein led to the rapid induction of autoantibodies. Therefore a more general note of caution regarding the use of highly immunogenic viral vector vaccines encoding such fusion proteins seems to be justified. In contrast, the coexpression of GM-CSF and antigens as two separate proteins in DNA prime adenoviral vector immunization regimens led to the enhanced induction of polyfunctional CD8+ T-cells, further supporting a potential application of GM-CSF as an adjuvant not only for DNA, but also for viral vector vaccines. Given the fact that the DNA prime adenoviral vector boost regimen is presently one of the most efficient ways to induce CD8+ T cell responses in mice, non-human primates and humans, the enhancement of this response by GM-CSF is a striking observation.

\section{Methods \\ DNA and adenoviral vector vaccines}

The DNA constructs used for the immunization studies are all based on the expression plasmid pcDNA3.1 (Invitrogen, Karlsruhe, Germany) or pShuttle-CMV [53]. The coding sequence of murine GM-CSF was amplified by RTPCR from RNA isolated from stimulated mouse splenocytes and cloned into the pCR-2.1-TOPO vector (Invitrogen). All other plasmids were constructed via standard cloning techniques including overlap extension PCR. Transgene expression is driven in all constructs by the immediate early promoter/enhancer region of human cytomegalovirus. The open reading frame of the fusion protein GM-OVA consisting of murine GM-CSF, a $\left[\mathrm{Gly}_{4} \mathrm{Ser}\right]^{3}$ linker and OVA was cloned into the pcDNA3.1 vector. pOVA, also a pcDNA3.1 derivative, encodes ovalbumin itself. Both proteins have a C-terminal $\mathrm{HIS}_{6}$-tag. The plasmids $\mathrm{pGM}^{\mathrm{rh}}-\mathrm{OVA}$, pGM-DP-OVA, and $\mathrm{p} \Delta \mathrm{GM}$ OVA are based on the pShuttle-CMV vector. The $\mathrm{GM}^{\mathrm{rh}}$ OVA fusion protein is equivalent to the mouse one with the sequence of murine GM-CSF being replaced by the rhesus monkey homologue. In the plasmid pGM-DPOVA, transgene expression is driven by a bidirectional version of the CMV/TetO2 promoter [54]. In $\mathrm{p} \Delta \mathrm{GM}-\mathrm{OVA}$ the coding sequence of ovalbumin is preceeded by the 17 amino acid long signal peptide of murine GM-CSF. All DNA preparations for immunizations were carried out with the Endofree Plamid Mega or Giga Kit (Qiagen, Hilden, Germany).
All E1-deleted, replication-defective adenoviruses with the corresponding expression cassettes (Ad-GM-OVA, AdGM-DP-OVA, Ad-rhGM-OVA, Ad- $\triangle$ GM-OVA) were generated by the AdEasy-system [53]. The pShuttle plasmids and pAdEasy1 were electroporated into BJ5183 bacteria as previously described [54]. Correctly recombined plasmids were transfected into 293 cells. Viral vectors growing out were checked for transgene expression by Western Blot analyses and GM-CSF bioactivity, if applicable. Vector particles were purified by $\mathrm{CsCl}$ gradient centrifugation and quantified by optical density measurements. In addition, the $\mathrm{TCID}_{50}$ of the vectors were determined on 293 cells. The adenoviral vector preparations were also tested for endotoxin levels with the LAL quantification assay (Cambrex Bio Science, Verviers, Belgium), confirming that the dose used for immunization of mice contained less than 0,1 EU.

\section{Cell culture media and reagents}

HEK293 and 293T cells were cultured in DMEM containing 10\% FCS and 1\% penicillin/streptomycin. RPMI 1640 supplemented with 10\% FCS, 2 mM L-Glutamine, $10 \mathrm{mM}$ HEPES, $50 \mu \mathrm{M} \beta$-Mercaptoethanol and 1\% antibiotic/ antimycotic (all Gibco, Karlsruhe, Germany) was used for the lymphocyte cultures (R10-medium). Bone-marrow cultures were grown in RPMI 1640, supplemented with $10 \%$ FCS, $1 \%$ penicillin/streptomycin, $4 \mathrm{mM} \mathrm{L-}$ Glutamine, $1 \mathrm{mM}$ sodium pyruvate and recombinant mouse IL-4 (1 ng/ml) and GM-CSF (5 ng/ml) (Biomol, Hamburg, Germany).

\section{Expression and bioactivity of GM-OVA}

293T cells were transfected using the calcium/phosphate precipitation method. Supernatants were collected $48 \mathrm{~h}$ after transfection and tested for protein expression by Western Blot analysis. A combination of rabbit- $\alpha$-OVA (Chemicon International, LTD, Hampshire, UK) and goat- $\alpha$-rabbit-HRP (Sigma, Munich, Germany) antibodies was used for detection. To confirm the bioactivity of GMOVA, it was purified from supernatants of transfected cells by Ni-NTA-affinity chromatography as described by the manufacturer (Qiagen, Hilden, Germany). The purified protein migrated as a single band of the expected size in Coomassie stained polyacrylamide gels. The GM-CSFdependent FDCP-1 cells were incubated with the purified GM-OVA or supernatants from NIH $3 \mathrm{~T} 3$ cells stably expressing GM-CSF. The GM-CSF content of the supernatants had been determined by ELISA. After 48 h, GM-CSFdependent cell growth was monitored by MTT-assay as described elsewhere $[55,56]$. Additionally, the ability to generate DCs from bone marrow cultures was tested as previously described [57]. Briefly, bone marrow derived monocytes were cultured in the prescence of IL- 4 and recombinant GM-CSF or GM-OVA for 8 days, with or without LPS maturation for $24 \mathrm{~h}$. Their phenotype was 
characterized by surface staining with the antibodies $\alpha$ CD11c-APC, $\alpha$-CD80-FITC, $\alpha$-CD86-FITC (all BD Bioscience, Heidelberg, Germany) and $\alpha$-CD83-PE (eBioscience, San Diego, USA) in FACS analyses.

\section{OT-I proliferation assay}

Splenocytes of transgenic OT-I mice were incubated with CFSE ( $3 \mu \mathrm{M}$; Molecular Probes, Eugene, Oregon, USA) at a density of $8 \times 10^{7}$ cells $/ \mathrm{ml}$ for $6 \mathrm{~min}$ at room temperature with gentle mixing. The labelling reaction was stopped by adding one volume of FCS after which the cells were washed twice with PBS. Thereafter, cells were plated into 96-well plates at a density of $1 \times 10^{6}$ cells/well and incubated with different concentrations of either GM-OVA or OVA ( 500 to $0,5 \mathrm{ng} / \mathrm{ml}$ ) for 4 days. After washing the cells twice with PBS containing 0,5\% BSA and $1 \mathrm{mM}$ sodium azide (PBS/BSA/Azid), cell proliferation was measured in FACS analysis. Cells, which were incubated with OT-I peptide, were used as positive controls whereas non-stimulated cells served as negative ones.

\section{Animals and immunizations}

6-8 week old female C57BL/6N mice were purchased from Janvier (Le Genest-ST-Isle, France) and housed in singly-ventilated cages in accordance with the national law and institutional guidelines.

All vaccines were diluted in PBS and injected subcutaneously in both hind foot pads. For single dose experiments, mice were immunized on day 1 with either $50 \mu \mathrm{g}$ of DNA (pOVA or pGM-OVA) or $5 \times 10^{9}$ adenoviral particles (Ad$\triangle$ GM-OVA resp. Ad-GM-OVA) corresponding to $2 \times 10^{8}$ $50 \%$ tissue culture infectious doses $\left(\mathrm{TCID}_{50}\right)$. After one week, serum samples were collected and on day 8 animals were sacrificed to analyze the CTL responses. In the primeboost experiments, all animals received an additional DNA injection (pOVA or pGM-OVA) 5 weeks prior to the above mentioned protocol. Serum samples were collected 28 days after the first and 7 days after the second immunization, whereas the T-cell assays were carried out 8 days after the second immunization.

\section{OVA specific antibody ELISA}

Blood was taken retro-orbitally and serum was collected after centrifugation for $5 \mathrm{~min}$ at $5.000 \mathrm{~g}$ in a table top centrifuge. Ovalbumin protein (Sigma) was coated on 96well plates (MaxiSorb, Nunc, Wiesbaden, Germany) at a final concentration of $5 \mu \mathrm{g} / \mathrm{ml}$. After blocking with $5 \%$ milk powder, serum samples were added at appropriate dilutions and incubated for $1 \mathrm{~h}$, followed by intensive washing. Alkaline phosphatase-coupled antibodies against mouse IgG1 or IgG2a antibodies (BD Bioscience) were added and incubated for $1 \mathrm{~h}$. The enzymatic reaction was developed with the pNPP substrate (Sigma) for 30 min. Reaction was stopped by sodium hydroxide solution
( $1 \mathrm{M}$ ) and the optical densities were measured at a wavelength of $405 \mathrm{~nm}$.

\section{Tetramer and intracellular cytokine staining (ICS)}

Splenocytes were collected at indicated time points. After red blood cell lysis, $1 \times 10^{6}$ cells were plated in 96-well round-bottom plates (Nunc) for each staining.

For the tetramer staining, cells were washed once and incubated with $2 \mu \mathrm{l}$ of SIINFEKL/H-2Kb-APC tetramers (Sanquin, Amsterdam, NL) in total volume of $100 \mu \mathrm{l} \mathrm{PBS/}$ BSA/Azid for $40 \mathrm{~min}$ at room temperature. After surface staining with $\alpha$-CD8-FITC, cells were incubated with 7 amino-actinomycin D (7-AAD) for 5 min to exclude dead cells from subsequent FACS analyses. In some experiments, $\alpha$-CD62L-PE antibodies were included in the tetramer analysis to characterize the $\mathrm{CD} 8^{+}$activation status.

For ICS, samples were stimulated for $6 \mathrm{~h}$ in the presence of $2 \mu \mathrm{M}$ Monensin, which inhibits the cytokine secretion, and $1 \mu \mathrm{l} \alpha$-CD107a-FITC, which is a marker for lymphocyte degranulation [32]. Cells were either stimulated by $\alpha$-CD3 and $\alpha$-CD28 antibodies $(2 \mu \mathrm{g} / \mathrm{ml}$ and $1 \mu \mathrm{g} / \mathrm{ml}$, respectively) or the OT-I/SIINFEKL peptide $(2 \mu \mathrm{g} / \mathrm{ml}$, Genaxxon, Biberbach, Germany) and compared to nonstimulated cultures. After stimulation, surface staining was carried out with $\alpha \mathrm{CD} 8$-PerCP or $\alpha \mathrm{CD} 4$-FITC (BD Bioscience). Cells were fixed in $2 \%$ paraformaldehyde, followed by permeabilisation with $0,5 \%$ Saponin in PBS/ BSA/Azid buffer. Cytokines were detected with $\alpha$ IFN- $\gamma$-PE and $\alpha$ IL-2-AlexaFluor647.

\section{Friend virus challenge and virus detection}

Mice were injected intravenously with $0.5 \mathrm{ml}$ phosphate buffered saline (PBS) containing 3,000 spleen focus-forming units (SFFU) of the Friend virus complex (FV). The Btropic, polycythemia-inducing $\mathrm{FV}$ complex used in all experiments was from uncloned virus stocks obtained from $10 \%$ spleen cell homogenates as described previously [58].

For infectious center assays, single-cell suspensions from infected mouse spleens were cocultivated with Mus dunnis cells at 10-fold dilutions. Cultures were incubated for 5 days, fixed with ethanol, stained with F-MuLV envelopespecific monoclonal antibody 720, and developed with peroxidase-conjugated goat antimouse antibody and aminoethylcarbazol to detect foci. Tetramer analyses were done by flow cytometry as described previously [59]. For the quantification of Friend virus-infected blood cells, single-cell suspensions of nucleated, live cells were analyzed by flow cytometry. To detect Friend virus infection cells were stained as described previously with tissue culture supernatant containing Friend murine leukemia virus gly- 
cosylated Gag-specific monoclonal antibody 34 (AB34) [60].

\section{Statistical analysis}

Results are expressed as the means \pm standard errors of the means (SEM). Statistical comparisons were performed by one-way ANOVA test, followed by a Bonferroni post test using the Prism 4.0, GraphPad Software. P $<0,05$ was considered as statistically significant.

\section{Authors' contributions}

MT participated in the design of the experiments, carried out the main part of the experiments, analyzed the data and wrote the manuscript with KÜ. BT established and performed the antibody ELISA, while SS and NG performed the Friend virus infection experiments. SK participated in the design of the study, adviced in the construction of the adenoviral vectors and provided assitance during the animal experiments. UD supported the study by critical discussions, designed the Friend virus infection experiments and critically reviewed the manuscript. KÜ designed and coordinated the study, contributed to interpretation of the data, and wrote the manuscript with MT. All authors read and approved the final manuscript

\section{Acknowledgements}

This work was supported by grants from the German Research Foundation (GK I045/I), the Wilhelm Sander Stiftung (2004.107.I), and the European Commission FP6 program (TIP-VAC, LSHP-CT-2004-012116).

\section{References}

I. Rosenberg ES, Altfeld M, Poon SH, Phillips MN, Wilkes BM, Eldridge RL, Robbins GK, D'Aquila RT, Goulder PJ, Walker BD: Immune control of HIV-I after early treatment of acute infection. Nature 2000, 407:523-526.

2. Jin X, Bauer DE, Tuttleton SE, Lewin S, Gettie A, Blanchard J, Irwin CE, Safrit JT, Mittler J, Weinberger L, Kostrikis LG, Zhang L, Perelson AS, Ho DD: Dramatic rise in plasma viremia after CD8(+) $T$ cell depletion in simian immunodeficiency virus-infected macaques. J Exp Med 1999, 189:991-998.

3. McMichael AJ: HIV vaccines. Annu Rev Immunol 2006, 24:227-255.

4. Wolff JA, Malone RW, Williams P, Chong W, Acsadi G, Jani A, Felgner PL: Direct gene transfer into mouse muscle in vivo. Science 1990, 247: 1465-1468.

5. Tang DC, DeVit M, Johnston SA: Genetic immunization is a simple method for eliciting an immune response. Nature 1992, 356: $152-154$.

6. Ulmer JB, Donnelly JJ, Parker SE, Rhodes GH, Felgner PL, Dwarki VJ, Gromkowski SH, Deck RR, DeWitt CM, Friedman A, .: Heterologous protection against influenza by injection of DNA encoding a viral protein. Science 1993, 259:1745-1749.

7. Gurunathan S, Klinman DM, Seder RA: DNA vaccines: immunology, application, and optimization*. Annu Rev Immunol 2000, 18:927-974.

8. Garmory HS, Brown KA, Titball RW: DNA vaccines: improving expression of antigens. Genet Vaccines Ther 2003, I:2.

9. Shiver JW, Fu TM, Chen L, Casimiro DR, Davies ME, Evans RK, Zhang ZQ, Simon AJ, Trigona WL, Dubey SA, Huang L, Harris VA, Long RS, Liang X, Handt L, Schleif WA, Zhu L, Freed DC, Persaud NV, Guan L, Punt KS, Tang A, Chen M, Wilson KA, Collins KB, Heidecker G], Fernandez VR, Perry HC, Joyce JG, Grimm KM, Cook JC, Keller PM, Kresock DS, Mach H, Troutman RD, Isopi LA, Williams DM, Xu Z, Bohannon KE, Volkin DB, Montefiori DC, Miura A, Krivulka GR, Lifton MA, Kuroda MJ, Schmitz JE, Letvin NL, Caulfield MJ, Bett AJ,
Youil R, Kaslow DC, Emini EA: Replication-incompetent adenoviral vaccine vector elicits effective anti-immunodeficiencyvirus immunity. Nature 2002, 415:33I-335.

10. MacGregor RR, Ginsberg R, Ugen KE, Baine Y, Kang CU, Tu XM, Higgins $T$, Weiner $D B$, Boyer JD: T-cell responses induced in normal volunteers immunized with a DNA-based vaccine containing HIV-I env and rev. AIDS 2002, 16:2I37-2I 43.

II. Seth A, Ourmanov I, Kuroda MJ, Schmitz JE, Carroll MW, Wyatt LS, Moss B, Forman MA, Hirsch VM, Letvin NL: Recombinant modified vaccinia virus Ankara-simian immunodeficiency virus gag pol elicits cytotoxic $T$ lymphocytes in rhesus monkeys detected by a major histocompatibility complex class I/peptide tetramer. Proc Natl Acad Sci U S A 1998, 95: I0I I 2-10II6.

12. Barouch DH, Pau MG, Custers JH, Koudstaal W, Kostense S, Havenga MJ, Truitt DM, Sumida SM, Kishko MG, Arthur JC, Korioth-Schmitz B, Newberg MH, Gorgone DA, Lifton MA, Panicali DL, Nabel GJ, Letvin NL, Goudsmit J: Immunogenicity of recombinant adenovirus serotype 35 vaccine in the presence of pre-existing antiAd5 immunity. J Immunol 2004, I72:6290-6297.

13. Yang ZY, Wyatt LS, Kong WP, Moodie Z, Moss B, Nabel G]: Overcoming immunity to a viral vaccine by DNA priming before vector boosting. J Virol 2003, 77:799-803.

14. Vuola JM, Keating S, Webster DP, Berthoud T, Dunachie S, Gilbert SC, Hill AV: Differential immunogenicity of various heterologous prime-boost vaccine regimens using DNA and viral vectors in healthy volunteers. J Immunol 2005, I 74:449-455.

15. Robinson HL, Amara RR: T cell vaccines for microbial infections. Nat Med 2005, I I:S25-S32.

16. Xiang Z, Ertl HC: Manipulation of the immune response to a plasmid-encoded viral antigen by coinoculation with plasmids expressing cytokines. Immunity 1995, 2:129-135.

17. Okada E, Sasaki S, Ishii N, Aoki I, Yasuda T, Nishioka K, Fukushima J, Miyazaki J, Wahren B, Okuda K: Intranasal immunization of a DNA vaccine with IL-I2- and granulocyte-macrophage colony-stimulating factor (GM-CSF)-expressing plasmids in liposomes induces strong mucosal and cell-mediated immune responses against HIV-I antigens. J Immunol 1997, 159:3638-3647.

18. Kim JJ, Simbiri KA, Sin JI, Dang K, Oh J, Dentcher T, Lee D, Nottingham LK, Chalian AA, McCallus D, Ciccarelli R, Agadjanyan MG, Weiner DB: Cytokine molecular adjuvants modulate immune responses induced by DNA vaccine constructs for HIV-I and SIV. J Interferon Cytokine Res 1999, 19:77-84.

19. Barouch DH, Santra S, Tenner-Racz K, Racz P, Kuroda MJ, Schmitz JE, Jackson SS, Lifton MA, Freed DC, Perry HC, Davies ME, Shiver JW, Letvin NL: Potent CD4+ $T$ cell responses elicited by a bicistronic HIV-I DNA vaccine expressing gp 120 and GM-CSF. J Immunol 2002, 168:562-568.

20. Geissler M, Gesien A, Tokushige K, Wands JR: Enhancement of cellular and humoral immune responses to hepatitis $C$ virus core protein using DNA-based vaccines augmented with cytokine-expressing plasmids. J Immunol I997, I 58: I23 I-I 237.

21. Lee SW, Cho JH, Sung YC: Optimal induction of hepatitis $\mathbf{C}$ virus envelope-specific immunity by bicistronic plasmid DNA inoculation with the granulocyte-macrophage colonystimulating factor gene. J Virol 1998, 72:8430-8436.

22. Sin Jl, Kim JJ, Ugen KE, Ciccarelli RB, Higgins TJ, Weiner DB: Enhancement of protective humoral (Th2) and cell-mediated $(T h I)$ immune responses against herpes simplex virus2 through co-delivery of granulocyte-macrophage colonystimulating factor expression cassettes. Eur J Immunol 1998, 28:3530-3540.

23. Bowne WB, Wolchok JD, Hawkins WG, Srinivasan R, Gregor P, Blachere NE, Moroi Y, Engelhorn ME, Houghton AN, Lewis J]: Injection of DNA encoding granulocyte-macrophage colony-stimulating factor recruits dendritic cells for immune adjuvant effects. Cytokines Cell Mol Ther 1999, 5:2 17-225.

24. Haddad D, Ramprakash J, Sedegah M, Charoenvit Y, Baumgartner R, Kumar S, Hoffman SL, Weiss WR: Plasmid vaccine expressing granulocyte-macrophage colony-stimulating factor attracts infiltrates including immature dendritic cells into injected muscles. J Immunol 2000, 165:3772-378I.

25. Miller G, Pillarisetty VG, Shah AB, Lahrs S, Xing Z, DeMatteo RP: Endogenous granulocyte-macrophage colony-stimulating factor overexpression in vivo results in the long-term recruitment of a distinct dendritic cell population with 
enhanced immunostimulatory function. J Immunol 2002, 169:2875-2885

26. Kusakabe $\mathrm{K}$, Xin KQ, Katoh H, Sumino K, Hagiwara E, Kawamoto $\mathrm{S}$, Okuda K, Miyagi Y, Aoki I, Nishioka K, Klinman D, Okuda K: The timing of GM-CSF expression plasmid administration influences the ThI/Th2 response induced by an HIV-I-specific DNA vaccine. J Immunol 2000, I64:3I02-3III.

27. Tao MH, Levy R: Idiotype/granulocyte-macrophage colonystimulating factor fusion protein as a vaccine for B-cell lymphoma. Nature 1993, 362:755-758.

28. Maecker HT, Umetsu DT, DeKruyff RH, Levy S: DNA vaccination with cytokine fusion constructs biases the immune response to ovalbumin. Vaccine 1997, 15:1687-1696.

29. Lima J, Jenkins C, Guerrero A, Triozzi PL, Shaw DR, Strong TV: A DNA vaccine encoding genetic fusions of carcinoembryonic antigen (CEA) and granulocyte/macrophage colony-stimulating factor (GM-CSF). Vaccine 2005, 23:| 273-। 283

30. Bonifaz LC, Bonnyay DP, Charalambous A, Darguste DI, Fujii S, Soares H, Brimnes MK, Moltedo B, Moran TM, Steinman RM: In vivo targeting of antigens to maturing dendritic cells via the $D E C$ 205 receptor improves $\mathbf{T}$ cell vaccination. J Exp Med 2004, 199:815-824.

31. Diebold SS, Kursa M, Wagner E, Cotten M, Zenke M: Mannose polyethylenimine conjugates for targeted DNA delivery into dendritic cells. J Biol Chem 1999, 274:19087-19094.

32. Betts MR, Brenchley JM, Price DA, De Rosa SC, Douek DC, Roederer $M$, Koup RA: Sensitive and viable identification of antigen-specific CD8+ $T$ cells by a flow cytometric assay for degranulation. J Immunol Methods 2003, 28I:65-78.

33. Sallusto F, Lenig D, Forster R, Lipp M, Lanzavecchia A: Two subsets of memory $T$ lymphocytes with distinct homing potentials and effector functions. Nature 1999, 401:708-712.

34. Wherry EJ, Teichgraber $\mathrm{V}$, Becker TC, Masopust D, Kaech SM, Antia $\mathrm{R}$, von Andrian $\mathrm{UH}$, Ahmed R: Lineage relationship and protective immunity of memory CD8 $\mathbf{T}$ cell subsets. Nat Immunol 2003, 4:225-234.

35. Ragnhammar P, Friesen HJ, Frodin JE, Lefvert AK, Hassan M, Osterborg $A$, Mellstedt $H$ : Induction of anti-recombinant human granulocyte-macrophage colony-stimulating factor (Escherichia coli-derived) antibodies and clinical effects in nonimmunocompromised patients. Blood 1994, 84:4078-4087.

36. Eisenblatter $M$, Stahl-Hennig $C$, Kuate $S$, Stolte N, Jasny E, Hahn H, Pope M, Tenner-Racz K, Racz P, Steinman RM, Uberla K, Ignatius R: Induction of neutralising antibodies restricts the use of human granulocyte/macrophage colony stimulating factor for vaccine studies in rhesus macaques. Vaccine 2004, 22:3295-3302

37. Wada $\mathrm{H}$, Noguchi $Y$, Marino MW, Dunn AR, Old LJ: T cell functions in granulocyte/macrophage colony-stimulating factor deficient mice. Proc Natl Acad Sci U S A 1997, 94: I2557-I256I.

38. Dittmer $U$, Hasenkrug $\mathrm{KJ}$ : Different immunological requirements for protection against acute versus persistent Friend retrovirus infections. Virology 2000, 272:177-182.

39. Dittmer U, Hasenkrug KJ: Cellular and molecular mechanisms of vaccine-induced protection against retroviral infections. Curr Mol Med 200I, I:431-436.

40. Gribben JG, Devereux S, Thomas NS, Keim M, Jones HM, Goldstone $\mathrm{AH}$, Linch DC: Development of antibodies to unprotected glycosylation sites on recombinant human GM-CSF. Lancet 1990 335:434-437.

41. Adelstein S, Pritchard-Briscoe H, Anderson TA, Crosbie J, Gammon G, Loblay RH, Basten A, Goodnow CC: Induction of self-tolerance in $T$ cells but not $B$ cells of transgenic mice expressing little self antigen. Science 199|, 25 I: | 223-I225.

42. Stevenson FK, Rice J, Ottensmeier CH, Thirdborough SM, Zhu D: DNA fusion gene vaccines against cancer: from the laboratory to the clinic. Immunol Rev 2004, 199:| 56-180.

43. Hertz M, Mahalingam S, Dalum I, Klysner S, Mattes J, Neisig A, Mouritsen S, Foster PS, Gautam A: Active vaccination against IL-5 bypasses immunological tolerance and ameliorates experimental asthma. J Immunol 200I, 167:3792-3799.

44. Chen TT, Levy R: Induction of autoantibody responses to GMCSF by hyperimmunization with an Id-GM-CSF fusion protein. J Immunol 1995, 154:3105-3117.

45. Thomassen MJ, Yi T, Raychaudhuri B, Malur A, Kavuru MS: Pulmonary alveolar proteinosis is a disease of decreased availability of GM-CSF rather than an intrinsic cellular defect. Clin Immunol 2000, 95:85-92.

46. Kitamura T, Tanaka N, Watanabe J, Uchida, Kanegasaki S, Yamada Y, Nakata K: Idiopathic pulmonary alveolar proteinosis as an autoimmune disease with neutralizing antibody against granulocyte/macrophage colony-stimulating factor. J Exp Med 1999, 190:875-880

47. Kim HD, Cao Y, Kong FK, Van Kampen KR, Lewis TL, Ma Z, Tang DC, Fukuchi K: Induction of a Th2 immune response by coadministration of recombinant adenovirus vectors encoding amyloid beta-protein and GM-CSF. Vaccine 2005, 23:2977-2986.

48. Deml L, Bojak A, Steck S, Graf M, Wild J, Schirmbeck R, Wolf H, Wagner $R$ : Multiple effects of codon usage optimization on expression and immunogenicity of DNA candidate vaccines encoding the human immunodeficiency virus type I Gag protein. J Virol 200I, 75: I099I-II00I.

49. Iwasaki A, Stiernholm BJ, Chan AK, Berinstein NL, Barber BH Enhanced CTL responses mediated by plasmid DNA immunogens encoding costimulatory molecules and cytokines. Immunol 1997, I 58:459|-460I.

50. McKay PF, Barouch DH, Santra S, Sumida SM, Jackson SS, Gorgone DA, Lifton MA, Letvin NL: Recruitment of different subsets of antigen-presenting cells selectively modulates DNA vaccineelicited CD4+ and CD8+ T lymphocyte responses. Eur J Immunol 2004, 34: I0II-1020.

5I. Santos K, Duke CM, Rodriguez-Colon SM, Dakwar A, Fan S, Keefer MC, Federoff HJ, Frelinger JG, Bowers W], Dewhurst S: Effect of promoter strength on protein expression and immunogenicity of an HSV-I amplicon vector encoding HIV-I Gag. Vaccine 2007, 25:1634-1646.

52. Zimmerli SC, Harari A, Cellerai C, Vallelian F, Bart PA, Pantaleo G: HIV-I-specific IFN-gamma/IL-2-secreting CD8 T cells support CD4-independent proliferation of HIV-I-specific CD8 T cells. Proc Natl Acad Sci U S A 2005, 102:7239-7244.

53. He TC, Zhou S, da Costa LT, Yu J, Kinzler KW, Vogelstein B: A simplified system for generating recombinant adenoviruses. Proc Natl Acad Sci U S A 1998, 95:2509-25।4.

54. Kuate S, Stefanou D, Hoffmann D, Wildner O, Uberla K: Production of lentiviral vectors by transient expression of minimal packaging genes from recombinant adenoviruses. J Gene Med 2004, 6:1197-1205

55. Mosmann T: Rapid colorimetric assay for cellular growth and survival: application to proliferation and cytotoxicity assays. J Immunol Methods 1983, 65:55-63.

56. Hansen MB, Nielsen SE, Berg K: Re-examination and further development of a precise and rapid dye method for measuring cell growth/cell kill. J Immunol Methods 1989, I I 9:203-2 I0.

57. Inaba K, Inaba M, Romani N, Aya H, Deguchi M, Ikehara S, Muramatsu S, Steinman RM: Generation of large numbers of dendritic cells from mouse bone marrow cultures supplemented with granulocyte/macrophage colony-stimulating factor. J Exp Med 1992, 176:1693-1702.

58. Hasenkrug KJ, Brooks DM, Robertson MN, Srinivas RV, Chesebro B: Immunoprotective determinants in friend murine leukemia virus envelope protein. Virology 1998, 248:66-73

59. Zelinskyy G, Robertson SJ, Schimmer S, Messer RJ, Hasenkrug KJ, Dittmer U: CD8+ T-cell dysfunction due to cytolytic granule deficiency in persistent Friend retrovirus infection. J Virol 2005, 79:10619-10626

60. Dittmer U, Peterson KE, Messer R, Stromnes IM, Race B, Hasenkrus $\mathrm{KJ}$ : Role of interleukin-4 (IL-4), IL- I2, and gamma interferon in primary and vaccine-primed immune responses to Friend retrovirus infection. J Virol 200I, 75:654-660. 